\title{
Rheumatoid lung sine arthritis - An unusual case mimicking idiopathic pulmonary fibrosis
}

\author{
J ason Chertoff, I slam Elgendy, I brahim Faruqi \\ Department of Internal Medicine, University of Florida College of Medicine, Gainesville, United States
}

Correspondence: Jason Chertoff. Address: Department of Internal Medicine, University of Florida College of Medicine, Gainesville, United States. Email: jason.chertoff@medicine.ufl.edu

Received: December 27, 2014

Accepted: January 21, $2015 \quad$ Online Published: January 22, 2015

DOI : $10.5430 /$ crim.v2n2p14

URL: http://dx.doi.org/10.5430/crim.v2n2p14

\begin{abstract}
We present the case of a 72-year-old male, with no history of connective tissue disease or musculoskeletal symptoms, who presented to our pulmonary clinic with five years of worsening dyspnea and presyncope with exertion. Pertinent findings on evaluation were computerized tomography of the chest showing diffuse honeycombing, pulmonary function tests demonstrating an intrinsic restrictive ventilatory defect, labs significant for an elevated C-reactive protein and erythrocyte sedimentation rate, and serologies remarkable for positive rheumatoid factor, positive anti-cyclic citrullinated peptide antibodies, and positive anti-nuclear antibody. Despite never having articular or other systemic manifestations of rheumatoid arthritis (RA), the patient was diagnosed with rheumatoid lung disease, started on definitive therapy and referred to rheumatology. An awareness of this unusual presentation of connective tissue related lung disease is critical to prevent misdiagnosis as idiopathic pulmonary fibrosis, so proper management and optimal patient outcomes are ensured.
\end{abstract}

\section{Keywords}

Interstitial lung disease, Rheumatoid arthritis, Idiopathic pulmonary fibrosis, Lung, Fibrosis

\section{Introduction}

In the United Kingdom, Rheumatoid arthritis (RA) affects at least $1 \%$ of the total population ${ }^{[1]}$. In addition to the commonly described articular manifestations of RA, pulmonary involvement occurs in approximately $7 \%$ of the patients with RA and is responsible for significant morbidity and $10 \%-20 \%$ of all mortality associated with the disease ${ }^{[2]}$. Studies have shown that in $80 \%-90 \%$ of patients RA presents with classic articular symptoms, while pulmonary involvement can be the initial presenting symptom in close to $10 \%$ of patients ${ }^{[2]}$. For those RA patients with pulmonary symptoms as their initial presentation, some will develop classic articular manifestations soon after diagnosis ${ }^{[3,4]}$. The patients that do notdevelop traditional RA symptoms will often carry an unclassified and ambiguous diagnosis ${ }^{[5]}$. In this report, we describe a case of rheumatoid lung presenting with pulmonary involvement for about 5 years with no reported history of articular or other systemic involvement.

\section{Case report}

A 72-year-old Hispanic male with no prior history of connective tissue disease presented toour quaternary care pulmonary clinic with a chief complaint of dyspnea and presyncope with exertion. Prior to this visit, his primary care physician and 
pulmonologist were following him over five years for progressively worsening dyspnea. Pertinent findings on his previous evaluation were significant for a computed tomography (CT) chest in 2009 that showed moderate honeycombing in both lower lobes and a repeat CT scan in 2013 that showed severe and diffuse honeycombing, significantly changed from his prior CT scan. Neither bronchoscopy nor lung biopsy were obtained before. His only pertinent medication prescribed by his pulmonologist was $\mathrm{N}$-acetyl-l-cysteine, which had been ineffective at symptom relief. His social history was significant for seventy pack-years of smoking, which he quit two years prior to presentation, and a remote history of exposure to insignificant amount of asbestos and acetone while in the army for two years. His family history was significant for an older brother who reportedly died from suspected interstitial pulmonary fibrosis (IPF), and reportedly found to have usual interstitial pneumonia (UIP) on autopsy.

Due to the worsening of his symptoms, he was referred to our clinic for further evaluation, management, and treatment of presumed IPF. Review of systems was positive for dyspnea at rest and presyncope with exertion, and negative for all other complaints including musculoskeletal and skin symptoms. Physical exam was remarkable for an oxygen saturation of $97 \%$ on room air at rest and fine inspiratory and expiratory crackles. Examination of the joints did not reveal any abnormality.

A six-minute walk test was unremarkable, with a normal walking distance and no oxygen desaturations. Pulmonary Function Tests (PFT) showed an intrinsic restrictive ventilatory defect and a marked reduction in the diffusing capacity, which was disproportionate to the degree of ventilatory impairment (FVC=3.3L-btps $-86 \%$ predicted, FEV1 $=2.57 \mathrm{~L}-$ $88 \%$ predicted, $\mathrm{FEV} 1 / \mathrm{FVC}=78 \%$, TLC $=4.52 \mathrm{~L}-71 \%$ predicted, $\mathrm{RV}=1.18 \mathrm{~L}-46 \%$ predicted, $\mathrm{DLCO}=39 \%$ predicted). A transthoracic echocardiogram (TTE) was significant for moderately elevated right-sided pressures and normal left ventricular systolic function. Laboratory evaluation was significant for an elevated C-reactive protein (CRP): $11.9 \mathrm{mg} / \mathrm{L}$ and erythrocyte sedimentation rate (ESR): $98 \mathrm{~mm} / \mathrm{h}$, and an unremarkable complete blood count, total serum protein, serum albumin and urea and electrolytes. Serology tests for autoimmune evaluation was remarkable for positive rheumatoid factor (RF): $542 \mathrm{IU} / \mathrm{ml}$, positive anti-cyclic citrullinated (anti-CCP): 26 units, and positive anti-nuclear antibody (ANA): 1:80, while the remainder of other autoimmune tests including C-Anti-Neutrophil Cytoplasmic, P-Anti-Neutrophil Cytoplasmic, anti-double stranded DNA, anti-Jo-1, antismooth muscle, anti-ribonucleotide antibodies being unremarkable. Despite never beingdiagnosed with RA or having articular symptoms, a diagnosis of rheumatoid lung was made.

Testing for tuberculosis and hepatitis was ordered in anticipation of methotrexate therapy. The patient was prescribed methotrexate, prednisone, double-strength sulfamethoxazole and trimethoprim, folic acid, and calcium/vitamin D supplementation.

The patient was referred to the rheumatology service and on follow up was seen in conjunction with a rheumatologist in our multi-disciplinary ILD clinic. In view of borderline renal function it was decided to change Methotrexate to Azathioprine for definitive treatment of rheumatoid lung.

\section{Discussion}

RA is an autoimmune disease that typically presents with symmetric synovitis and arthritis.

In addition to articular symptoms, approximately $40 \%$ of patients have extra-articular involvement, with close to $7 \%$ developing lung disease over their lifetime ${ }^{[6,7]}$. Risk factors that aggravate ILD development in RA patients include older age, male sex, smoking (which is considered the main preventable risk factor), and the underlying severity of the articular disease ${ }^{[7,8]}$. Rheumatoid lung is a typical sequela of RA lung involvement that usually presents with worsening dyspnea due to progressive fibrosis. When compared to RA patients without RA-Related ILD (RA-ILD), those with RA-ILD have an estimated standardized mortality ratio of 2.5 to $5.0^{[9]}$. 
Of the small subsection of the population that develops RA pulmonary manifestations, only $10 \%$ initially present without articular symptoms ${ }^{[2]}$. Gizinski et al described 4 patients with RF and anti-CCP antibodies and no articular signs or symptoms. After 2 years of follow-up, only 1 of these patients developed articular RA, with the other 3 patients had died ${ }^{[3]}$. Fischer et al followed 74 patients with pulmonary symptoms, positive anti-CCP antibodies, and no symptoms of RA or connective tissue disease for 2 years. Of these patients, 3 developed articular symptoms after a mean follow-up of 449 days ${ }^{[4]}$. Similar to the other cases in the literature, our patient was an elderly male with a long history of smoking, positive RF and anti-CCP antibodies, and no evidence of articular involvement. However, our case is unique in that the patient has been followed for 5 years without articular involvement, which to our knowledge is the longest follow-up period reported in the literature, with both Gizinski et al and Fischer et al reporting follow-up periods of 2 years or less ${ }^{[3,4]}$.

Several histopathologic subtypes of ILD are known to be associated with RA (RA-ILD) but by far the most common subtypes are UIP and non-specific interstitial pneumonia (NSIP). In RA-ILD, UIP pattern on CT scan has been shown to be highly specific for UIP pattern on histopathology, which in turn is associated with worse survival compared to those without a UIP pattern ${ }^{[10]}$. It is not well known why some patients might develop ILD without any preceding articular manifestations; many investigators have proposed different hypotheses to explain this unique subsection of RA patients. Bongartz et al hypothesized that citrullination was responsible for the pulmonary manifestations of RA, as significantly more RA-ILD patients showed citrullination on lung biopsy than matched controls ${ }^{[11]}$. Makrygiannakis et al concluded that smoking might be an environmental factor that can lead to citrulline autoimmunity and the development of autoimmune lung disease ${ }^{[12]}$. Others have proposed that smoking, in the presence of HLADRB1* SE, may lead to CCP autoimmune lung involvement in genetically susceptible individuals ${ }^{[13]}$.

There is some lack of clarity regarding classification of a patient with Interstitial Lung Disease who has clinical features or serology suggestive of a connective tissue disorder (CTD) but does not meet the established criteria for the said CTD. Fisher et al discussed this diagnostic dilemma at length citing significant amount of evidence and proposed a new set of "Provisional Criteria for Lung-Dominant CTD" ${ }^{[5]}$. Our patient would be classified to have Lung Dominant-RA as per these criteria.

Our case describes a patient with a unique presentation of RA-ILD in that he had been without classic articular symptoms for greater than 5 years. Due to this uncommon presentation, little is known about the pathophysiology and optimal management and treatment of these patients. Regardless of its mechanism, researchers and clinicians should be aware of this unusual and debilitating presentation of RA so that misdiagnosis as IPF can be prevented, and improved treatment strategies can be discovered and implemented.

\section{References}

[1] Humphreys JH, Verstappen SM, Hyrich KL, et al. The incidence of rheumatoid arthritis in the UK: comparisons using the 2010 ACR/EULAR classification criteria and the 1987 ACR classification criteria. Results from the Norfolk Arthritis Register. Ann Rheum Dis. 2013; 72: 1315-20. PMid:22945499 http://dx.doi.org/10.1136/annrheumdis-2012-201960

[2] Brown KK. Rheumatoid lung disease. Proc Am Thorac Soc. 2007; 4: 443-8. PMid:17684286

http://dx.doi.org/10.1513/pats.200703-045MS

[3] Gizinski AM, Mascolo M, Loucks JL, et al. Rheumatoid arthritis (RA)-specific autoantibodies in patients with interstitial lung disease and absence of clinically apparent articular RA. Clin Rheumatol. 2009; 28: 611-3. PMid:19252818 http://dx.doi.org/10.1007/s10067-009-1128-9

[4] Fischer A, Solomon JJ, du Bois RM, et al. Lung disease with anti-CCP antibodies but not rheumatoid arthritis or connective tissue disease. Respir Med. 2012; 106: 1040-7. PMid:22503074 http://dx.doi.org/10.1016/j.rmed.2012.03.006

[5] Fischer A, West SG, Swigris JJ, et al. Connective tissue disease-associated interstitial lung disease: a call for clarification. Chest. 2010; 138: 251-6. PMid:20682528 http://dx.doi.org/10.1378/chest.10-0194 
[6] Mori S, Cho I, Koga Y, et al. Comparison of pulmonary abnormalities on highresolution computed tomography in patients with early versus longstanding rheumatoid arthritis. J Rheumatol. 2008; 35: 1513-21. PMid:18597412

[7] Bongartz T, Nannini C, Medina-Velasquez YF, et al. Incidence and mortality of interstitial lung disease in rheumatoid arthritis: a population-based study. Arthritis Rheum. 2010; 62: 1583-91. PMid:20155830 http://dx.doi.org/10.1002/art.27405

[8] Gochuico BR, Avila NA, Chow CK, et al. Progressive preclinical interstitial lung disease in rheumatoid arthritis. Arch Intern Med. 2008; 168(2): 159-166. PMid:18227362 http://dx.doi.org/10.1001/archinternmed.2007.59

[9] Fischer A, du Bois R. Interstitial lung disease in connective tissue disorders. Lancet. 2012; 380: 689-98. http://dx.doi.org/10.1016/S0140-6736(12)61079-4

[10] American Thoracic Society; European Respiratory Society. American Thoracic Society/European Respiratory Society International Multidisciplinary Consensus Classification of the Idiopathic Interstitial Pneumonias. This joint statement of the American Thoracic Society (ATS), and the European Respiratory Society (ERS) was adopted by the ATS board of directors, June 2001 and by the ERS Executive Committee, June 2001. Am J Respir Crit Care Med. 2002; 165: 277-304. PMid:11790668 http://dx.doi.org/10.1164/ajrccm.165.2.ats01

[11] Bongartz T, Cantaert T, Atkins SR, et al. Citrullination in extra-articular manifestations of rheumatoid arthritis. Rheumatology. 2007; 46: 70-5. PMid:16782731 http://dx.doi.org/10.1093/rheumatology/kel202

[12] Makrygiannakis D, Hermansson M, Ulfgren AK, et al. Smoking increases peptidylarginine deiminase 2 enzyme expression in human lungs and increases citrullination in BAL cells. Ann Rheum Dis. 2008; 67: 1488-92. PMid:18413445 http://dx.doi.org/10.1136/ard.2007.075192

[13] Aubart F, Crestani B, Nicaise-Roland P, et al. High levels of anti-cyclic citrullinated peptide autoantibodies are associated with co-occurrence of pulmonary diseases with rheumatoid arthritis. J Rheumatol. 2011; 38: 979-82. PMid:21362759 http://dx.doi.org/10.3899/jrheum.101261 